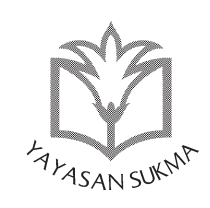

SUKMA: JURNAL PENDIDIKAN

ISSN: 2548-5105 (p), 2597-9590 (e)

Volume 3 Issue 2, Jul-Dec 2019, pp. 187-202

https://doi.org/10.32533/03203.2019

www.jurnalsukma.org

\title{
MOTIVATIONAL FACTORS TO LEARN ENGLISH AMONG UNIVERSITY STUDENTS IN AN URBAN AREA
}

\section{Reza Anggriyashati Adara}

Universitas Islam 45 Bekasi, Indonesia

email: reza.adara@gmail.com

\section{Abstract}

Motivation can be considered as one of influential factors in foreign language (FL) learning as it helps to sustain learner's interest during long and tedious learning process of FL. According to Deci and Ryan (2000), motivation can be categorized into two types; intrinsic and extrinsic motivation. The present study aims to investigate intrinsic and extrinsic motivational factors of a group of university students in an urban area to learn English. The present study applied a mixed method approach by administering a set of questionnaires and interviews. In addition to a 
relatively high level of motivation among the participants, the findings of present study show an interest in English language skills and positive attitudes to native speakers of English, English speaking countries, and English learning as intrinsic motivational factors to learn English. On the other hand, the chances of getting better jobs and personal development as extrinsic factors which motivate students to learn English. The present study recommends English teachers as well as educational institutions to provide teaching and learning materials which suited to improve students' motivation.

Keywords: intrinsic motivation, extrinsic motivation, foreign language learners, urban area

\section{A. Introduction}

Despite the status of English as a FL (Foreign Language) in Indonesia, there is a growing trend to learn English among Indonesians which due to its position as a global language. In 2003, the Ministry of Education of Indonesia introduced the concept of International Standard School in which English is used as medium of instruction for certain school subjects such as science and mathematics in order to enhance the nation's ability to compete globally (Coleman 2011). Although the concept of English as medium of instruction is not applied to all schools in Indonesia, Jalal \& Musthafa (2001) reported that English has been included as one of fields of study at schools in Indonesia. Several factors can be attributed to this trend. Firstly, English is considered as a global language. Graddol (2006) reasoned that rapidly changing world encouraged the adoption of English. It is due to the position of English as a global language which allows communication among people of different nations. Furthermore, people depend on English for their economic and social well-being as English has been used in international domains of 
political life, business, safety, communication, entertainment, the media and education (Crystal 2003, 29). As a part of the world, Indonesians need to communicate with people from all over the world for knowledge and economic exchange. Hence, the trend to learn English in Indonesia, despite its status as FL, might be due to its position as global language which serves as a medium for improving socio-economic standing.

Besides its status as a global language, there are many factors which motivate Indonesian learners to learn English. These factors have been investigated in many studies. Lamb (2007) examined motivational factors of a group of junior high school students in provincial area in Indonesia to learn English. Besides indicating high levels of motivation among students, the findings of Lamb's (2007) study implied the influences of internal (motivational self-regulation, future goals, gender) and external (world events, socio-economic background, family, teachers, peers) factors to students' motivation in learning English. In another study, Lamb (2012) analysed the motivation of 527 junior high school students in Indonesia to learn English. The findings of his study in 2012 implied positive views of English learning experience as the strongest factor which influenced students' motivation to learn English. A study of Beath (2010) about language learning motivation of a female Indonesian language learner indicated the change in internal as well as external factors which motivate her to learn English. The above studies show how different factors can affect students' motivation to learn English.

Investigating students' motivation might help teachers and researchers to understand it better and provide better English learning. Beath (2010) argued that it is imperative to study motivation of different groups of learners due to its complex, multi-faceted construct which still undergoes shaping and redefining phases as it is applied to different groups of learners. Hence, investigating various learners might benefit researchers with deeper insights to students' motivation to learn English. It is why several studies targeted different types of students in different areas. In 2012, Lamb's study focused on the comparison 
of learners' motivation from three different areas in Indonesia; a metropolitan city, a provincial town, and a rural district. A study of Nichols (2014) analysed motivational strategies of a group of Chinese students in Jakarta, a metropolitan city. Besides the above studies, Lamb \& Budiyanto (2013) researched cultural challenges, identity, and motivation of state school in a provincial area in Indonesia. Those studies indicate multi-faceted sides of motivation.

Despite above studies, there is scarcity of studies toward the motivation of English learners in an urban area of Indonesia. Thus, the present study attempts to fill the scarcity by investigating factors which motivate university students in an urban area in Indonesia to learn English. The lack of studies toward university students, especially ones from Bekasi, becomes a factor that makes the present study specifically analyse them. The present study attempts to answer following questions; what intrinsic and extrinsic factors motivating university students to learn English and what the level of motivation of a group of university students to learn English.

\section{B. Factors Influencing Foreign Language (FL) Learning Motivation}

One of influential factors in FL learning is motivation. In this consideration, motivation refers to a combination of desires which influence someone to achieve the goal and are reflected on their efforts (Ellis 1994; Harmer 2001; Oxford \& Shearin 1994; Ryan \& Deci 2000). Motivation is a significant factor in FL learning as it sustains learners' interests during learning process. Besides that, an effective language acquisition can be achieved if learner's preferences with classroom activities and motivation in English language learning are matched (Mulalic \& Obralic 2016). Due to its importance, motivation in FL learning has been investigated in several studies (Cerqueira \& Badger 2015; Dörnyei \& Csizér 2002; Juriševič \& Pižorn 2013). It can be said that motivation in FL learning is significant because it can influence learner's interest and efforts to master FL. 
There are many factors influencing motivation in FL learning. Those factors can be categorized into intrinsic and extrinsic factors. While intrinsic factors can be defined into beliefs related to language learning (Madrid 1995, 65), extrinsic factors refer to factors which influenced by outward variables such as school, peers, or teachers (Lamb 2007, 78). Some researchers have investigated intrinsic and extrinsic factors in FL learning. The findings of Moskovsky \& Alrabai's (2009) study toward a group of English learners in Saudi Arabia showed positive attitudes as intrinsic factors which motivate them to learn English as a FL. Besides that, the findings of Lucas et al' (2010) study toward 240 college students in Philippines showed an interest to certain language skills which students found as interesting and relevant to them as an intrinsic motivational factor. On the other hand, a study of Lamb (2004) toward a group of students in a rural area of Indonesia indicated teachers and peers as one of extrinsic factors which motivated students to learn English. In addition, a study of Khazaie \& Mesbah (2004) showed a chance of getting a job as one of extrinsic factors which motivate a group of English learners in Iran to learn FL.

\section{Extrinsic Motivation in Learning English}

This section aims to discuss the findings obtained from questionnaires and interviews. The findings related to extrinsic factors which motivate the participants to learn English will be discussed before the intrinsic ones. Lastly, the findings related to the participants' level of motivation will be discussed.

All participants (20) agreed with the statement 1: "I learn English in order to get a better job" and with the statement 4: "I learn English because I think it is good for my personal development"; whereas only one participant disagreed with the statement 2: "I learn English in order to have a better salary later" and with the statement 5: "I learn English because I like my English teachers." Towards the statement 3: "I learn English because I want to get better grades," 18 out of 20 participants 
agreed with it. The above results indicate some extrinsic factors which motivate the participants to learn English. Those factors are a chance of getting a job, better salary, better grades, personal development, and teachers. Although most participants show positive reaction, all participants agreed that they learned English to get better job and for their own personal development. The statement is quite similar with following comments from the interviews' participants.

Student A: "Well, personally I am interested in learning English because I would like to know deeper and deeper about English and the additional thing is of course I would like to get a good job."

Student B: “...because if I learn English, I can get a better job and better salary."

The findings imply that the participants think those factors are ones that motivate them the most to learn English. It is quite similar to the findings of Kreishan \& Dhaimat's (2013) study of a group of Jordanian learners' intrinsic and extrinsic motivation and instrumental and integrative orientations toward learning foreign languages. The findings show getting more job opportunities and a chance to communicate with the world as factors which motivate the participants in Kreishan and Dhaimat's (2013) study to learn foreign languages. A study of Poornima et al. (2016) also shared almost similar result. The participants of Poornima et al's (2016) study indicated getting better jobs, travelling, and teachers as some external factors which motivate them to learn FL. Related to travelling and a chance to communicate with people all over the world, the participant of the present study also expressed almost similar answer with the participant of Poornima et al's (2016) study.

Student A: "I feel that English is very special because when we are mastering English of course we can communicate with people from all over the world and... I also have some dreams that I can go abroad like (a lecturer)..." 
In addition to getting better jobs and personal development, the participants of the present study indicate a chance to visit and communicate with people from other countries as extrinsic factors which motivate them to learn English. The similarities among the findings of present study and previous studies indicate a pattern that most FL learners might be extrinsically motivated due to a chance of getting better jobs and develop themselves.

Regarding the above paragraph, participants thought that being fluent in English might help getting better chances in workforces. This might be related to students' learning context which is located in an urban area. Similarly, a study of Lamb (2012) on motivation of Indonesian EFL students in three different places (a metropolitan city, a provincial town and a rural district) indicate that participants in a metropolitan city and a provincial town seem to be more motivated to learn English due to external factors such as getting jobs. Lamb (2012) argued that the more the participants know the usefulness of English for their life, they will be more motivated to learn English. Thus, in order to improve students' motivation in an urban area such as one in the present study, teachers can use materials related to work-force such as writing formal emails, preparing for job interviews, presenting ideas in meetings and else. Besides catering to students' interests, it will provide them with English skills needed in daily life. Besides preparing them for work-force, this approach might help students developing their English skills.

\section{Intrinsic Motivation in Learning English}

Intrinsic motivational factors relate to pleasure and good feeling that the participants experienced in learning and practicing English. The research shows that 19 out of 20 participants agreed with the statement 6: "I learn English for the pleasure I experience when I do well in English" and with the statement 7: "I learn English for the enjoyment I experience when I understand a difficult idea in English." There are 17 out of 20 participants 
agreed with the statement 8: "I learn English for the satisfied feeling when I accomplish difficult exercises in English." Meanwhile, on the statement 9 and 10: "I learn English for the good feeling when I hear English spoken" and "I learn English for the good feeling when I speak English," all participants showed their agreement. It indicates some intrinsic factors which motivate the participants of the present study to learn English. Those factors are the pleasure of doing well in English, enjoyment of knowing difficult idea in English, satisfied feeling when accomplishing difficult exercises in English, the good feeling when hearing spoken English, and the good feeling when speaking English. Most participants showed positive reactions to those factors but all of them agreed that they are mostly motivated to learn English due to pleasure of hearing spoken English and the good feeling they get when they speak English. It can be said that they are quite motivated due the aspect in speaking and listening skills of English.

The results of Lucas' (2009) study also showed students' interest in learning language skills, especially speaking, listening and reading skills as factors which motivate them to learn English. These similarities indicate students' interest in learning speaking and listening skills of English. In this consideration, teachers might provide more materials related to these skills to incite students' motivation in learning English. On the other hand, Lamb's (2007) study on a group of Indonesian high school students in a provincial area of Indonesia indicated intrinsic factors such as motivational self-regulation, ideal L2 self and gender. The findings of present study and Lamb's (2007) study indicate the differences in intrinsic factors of students in rural and urban areas of Indonesia. It can be said that teachers should consider their teaching location before motivating their students.

In addition to the above mentioned intrinsic factors, positive attitudes toward native speakers and English speaking countries are also shown by the participants of the present study. Such attitudes might attribute to the participants' motivation to learn English. There are 18 out of 20 participants agreed that "I learn English because I enjoy knowing about American or British soci- 
eties and their ways of life." Whereas, 15 participants agreed that "I learn English because I like having native speakers as friends." It indicates the participants' positive attitudes toward native speakers and English speaking countries. Following comments also suggest similar idea.

Student B: "I think native speakers or culture of English speaking countries is amazing."

Student B: "Yes, I want to know more about these native speakers."

The participants on Alshaar's (1997) study on attitudes and motivation of a group of second language learners in Kuwait as well as Muftah and Rafik-Galea (2013) on a group of Malaysian students also showed positive attitudes to target language's culture and community. In addition to the positive attitudes toward English speaking countries and native speakers, the participants showed positive attitudes to learning English. Below figures show the attitudes of participants to English learning.

Concerning participants' attitudes towards learning English, all participants agreed that learning English is really great and they really enjoy it. Meanwhile, 17 participants disagree that learning English is only wasting time. Similarly, 18 participants shown their disagreement that "I think that learning English is dull." This data suggest the participants' positive attitudes to English learning. Similar positive attitudes were also shown in the findings of Moskovsky \& Alrabai's (2009) to English learners in Saudi Arabia. The findings of Che Mat \& Yunus's (2014) study on a group of English learners in Malaysia also indicated positive attitudes to English learning among the participants. The aforementioned findings show that positive attitudes either to native speakers and English speaking countries or English learning can be quite significant factors that influence students' motivation in learning English. Thus, teachers or teaching institutions can provide more focus on stimulating students' positive attitudes. It can be done by providing more positive information about the 
culture of English speaking countries to students or giving more interesting classroom activities.

\section{Motivational Intensity}

Positive attitudes shown by the participants of the present study might be related to their level of motivation to learn English. Following are the findings related to the participants' level of motivation to learn English.

All 20 participants agreed with the statement that "I make a point of trying to understand all the English I see and hear," whereas 16 out of 20 participants agreed with the statement that "I can't be bothered trying to understand the more complex aspects of English." Among the participants, there is only 1 person that does not keep up to date with English by working on it almost every day;" and 18 out of 20 participants don't bother checking their corrected assignments in their English courses. The findings indicate a relatively high level of motivation to learn English among the participants and similar to the following interviews' findings.

Student A: "Yes, absolutely, I'm extremely super motivated to learn English compared to all of my classmates because of why? Because I feel that I have err good enough, I mean, I mean my English is good enough compared to all of my classmates and I really believe that through English I can get what I really want. I mean I can continue my study to umm abroad and I can share what I get, I mean I can share my knowledge to my students."

Student B: "I think learning English is fun because it's my passion and I think I'm motivated enough to learn English compared to all of my classmates."

The findings of present study were in accordance with many studies related to the level of motivation to learn English. The findings of a study of Liu \& Zhang (2013) toward a group of university students in China suggest a high level of motivation 
to learn English and the findings of Lamb's (2007) study also indicate a high level of motivation among a group of high school students in a provincial area in Indonesia.

\section{Limitations and Further Research}

The study is not without some limitations. Firstly, the number of participants might not represent the population of Bekasi. Conducting further studies which involve wider sample of population is an important next step for researchers of this field. In addition, this study only applied interviews and questionnaires. Other research instruments such as classroom observation might provide deeper findings on this matter. Lastly, this study would benefit from longer research time to see if the students' motivation might change with time.

Despite the limitations, this study can be a stepping stone for possible studies. The present study's findings indicate that either intrinsic or extrinsic factors can affect the motivation level of a group of university students in an urban area. In general, these findings might provide more insights toward the studies of motivation, especially ones of Indonesian students in urban areas. However, the findings of present study might not represent all factors which motivate the students in all urban areas. There are many factors such as country, culture, and education level that can contribute to the diversity of those factors. For example, factors which motivate Indonesian students can be different from Malaysian students. Thus, it is important to conduct more studies related to students' motivation in various areas. In addition, possible studies might gain more insights by comparing students' motivation and factors in urban and rural areas of Indonesia. Although Lamb (2012) has performed such study toward a group of students in urban and rural areas in Sumatra, Indonesia, it would be interesting to perform similar study in Java or other islands in Indonesia, providing more diverse contexts in students' motivation. 


\section{Conclusion}

Despite the status of English as a foreign language in Indonesia, this subject has become a popular one due to few factors such as the status of English as a global language, the need to communicate with people from other countries, and else. The present study analysed the motivation of university students due to the importance of motivation. Specifically, this study discussed intrinsic and extrinsic factors which motivate university students to learn English in an urban area of Indonesia. In addition, the level of students' motivation was also investigated. The university students in Bekasi were chosen as the participants of the present study due to lack of studies which specifically analyse them. To investigate the matter, the present study used a mixed method approach by distributing questionnaires to twenty university students and conducting interviews to two of the participants. Besides indicating a relatively high level of motivation among the participants, the findings show intrinsic factors such as the interest in language skills of English, positive attitudes toward English speaking countries and the native speakers, as well as English language learning that motivate the participants to learn English. On the other hand, the findings show a chance of getting better jobs and personal development as extrinsic factors of students' motivation. The present study recommends teachers to include motivational factors in learning materials to improve students' motivation.

\section{BIBLIOGRAPHY}

Alshaar, B. E. 1997. Attitudes and motivation of second language learners in Kuwait. Retrospective Theses and Dissertations. Paper 277.

Beath, O. 2010. "I Want to be More Perfect Than Others: a Case of ESL Motivation." Paper presented at the Faculty of Education and IERI HDR Conference, University of Wollongong, 12 November 2010. 
Motivational Factors to Learn English among University Students

Cerqueira, F. A \& S. Badger. 2015. "Language motivation and attitudes: a study with English for Academic Purposes learners." Horizontes de Linguística Aplicada 14 (1), 135-171.

Che Mat, S. S \& M. D. Yunus. 2014. "Attitudes and motivation towards learning English among FELDA school students." Aust. J. Basic \& Appl. Sci. 8 (5), 1-8.

Coleman, H. 2011. "Allocating resources for English: The case of Indonesia's English medium international standard schools." In Dreams and realities: Developing countries and the English language. Edited by H. Coleman. London: The British Council.

Collins, K. M. T., A. J. Onwuegbuzie \& Q. G. Jiao. 2006. "Prevalence of mixed methods sampling designs in social science research." Evaluation and Research in Education 19, 83-101.

Creswell, J. W. 1994. Research Design Qualitative and Quantitative Approaches. London: Sage Publications.

Crystal, D. 2003. English as a global language. Cambridge: Cambridge University Press.

Deci, E. L. \& R. M. Ryan. 1985. Intrinsic motivation and selfdetermination in human behavior. New York, NY: Plenum.

Dörnyei, Z. 1990. "Conceptualizing motivation in foreign language learning." Language Learning 40, 46-78.

Dörnyei, Z. \& K. Csizér. 2002. "Some dynamics of language attitudes and motivation: Results of a longitudinal nationwide survey." Applied Linguistics 23 (4), 421-462.

Ellis, R. 1994. The Study of Second Language Acquisition. Oxford: Oxford University Press.

Fielding N. \& Fielding J. 1986. Linking data. London: SAGE.

Graddol, D. 2006. "English Next: Why global English may mean the end of "English as a Foreign Language." The British Council. Retrieved from http://vigdis.hi.is/sites/vigdis.hi.is/files/ images/einangrun_enskumaelandi_folks.pdf

Greene, J. C., V. J. Caracelli \& W. F. Graham. 1989. "Toward a conceptual framework for mixed-method evaluation designs." Educational Evaluation and Policy Analysis 11, 255-274. 
Jalal, F. \& B. Mustafha. 2001. Education Reform in the Context of Regional Autonomy: The Case of Indonesia. Jakarta: MoNE, BAPPENAS \& World Bank.

Johnson, R. B. \& A. J. Onwuegbuzie. 2004. "Mixed Methods Research: A Research Paradigm Whose Time Has Come." Educational Researcher 33 (7), 14-26.

Juriševič, M \& K. Pižorn. 2013. "Young Foreign Language Learners' Motivation - A Slovenian Experience." Porta Linguarum 19, 179-198.

Khazaie, Z. M \& Z Mesbah. 2014. "The Relationship between Extrinsic vs. Intrinsic Motivation and Strategic Use of Language of Iranian Intermediate EFL Learners." Theory and Practice in Language Studies 4 (1), 99-109.

Kreishan, L.J. \& Y. Al-Dhaimat. 2013. "Intrinsic and extrinsic motivation, orientation and achievements in 12 of Arab learners of English, French and German: A study from Jordan." International Education Studies 6 (12), 52-63.

Lamb, M.V. 2007. The motivation of junior high school pupils to learn English in provincial Indonesia. PhD Thesis. University of Leeds.

Lamb, M. V. 2012. "A Self System Perspective on Young Adolescents' Motivation to Learn English in Urban and Rural Settings." Language Learning 62 (4), 997-1023.

Lamb, MV \& Budiyanto. 2013. "Cultural Challenges, Identity and Motivation in State School EFL." In International Perspectives on Motivation. International Perspectives on English Language Teaching. Macmillan: Palgrave.

Lucas, R.I et al. 2010. "A study on the intrinsic motivation factors in second language learning among selected freshmen students." Philippine ESL Journal 4, 3-23.

Madrid, D. 1995. "Internal and External Factors in Language Teaching." Actas de las 1I Jornadas de Estudios Ingleses. Universidad de Jaén, 59-82.

Maxwell, J. 1992. "Understanding and Validity in Qualitative 
Research." Harvard Educational Review 62 (3), 279-301.

Moskovsky, C., \& F. Alrabai. 2009. "Intrinsic motivation in Saudi learners of English as a foreign language." The Open Applied Linguistics Journal 2, 1-10.

Muftah, M \& S. Rafik-Galea. 2013. "Language Learning Motivation among Malaysian Pre-University Students." English Language Teaching 6 (3), 92-103.

Mulalic, A \& N Obralic. 2016. “The Relationship between Motivation Components and Preferred Learning Components among Students at International University of Sarajevo." Epiphany: Journal of Transdisciplinary Studies 9(1), 75-83.

Nichols, R. 2014. Motivating English Language Learners: An Indonesian Case Study. Master of Education Program Theses. Paper 52.

Oletić, A \& N Ilić. 2014. "Intrinsic and Extrinsic Motivation for Learning English as a Foreign Language." ELTA Journal 2 (2), 23-38.

Oxford, R., \& , J. Shearin. 1994. "Language learning motivation: Expanding the theoretical framework." Modern Language Journal 78, 12-28.

Pae, T. 2016. "Effects of the differences between native and nonnative English-speaking teachers on students' attitudes and motivation toward learning English." Asia Pacific Journal of Education, 1-16.

Poornima. B, et al. 2016. "Factors Influencing Second Language Learning Among Urban European Language Learners: A Qualitative Study." The International Journal of Indian Psychology 3 (7), 43- 51.

Ryan, R. M., \& E. L. Deci. 2000. "Self-determination theory and the facilitation of intrinsic motivation, social development, and well-being." American psychologist 55(1), 68.

Srithongkham, K \& U. Sucaromana. 2013. "Intrinsic Motivation: A Study of Students Learning English as a Foreign Language." New English Teacher 7(1), 90-101. 
Reza Anggriyashati Adara

Yeasmin, S \& Khan F. R. 2012. "Triangulation Research Method as the Tool of Social Science Research." BUP Journal 1 (1), 154163. 